\title{
BIBLIOGRAPHY OF PROFESSOR NENAD MOAČANIN
}

\section{by Vjeran Kursar}

\section{BOOKS}

1. Požega i Požeština u sklopu Osmanlijskoga carstva (1537.-1691.), Jastrebarsko: Naklada Slap, 1997, 544 pp.

2. Turska Hrvatska, Zagreb: Matica hrvatska, 1999, 211 pp.

3. Slavonija i Srijem u razdoblju osmanske vladavine, Slavonski Brod: Hrvatski institut za povijest, Podružnica za povijest Slavonije, Srijema i Baranje, 2001, 202 pp.

4. Town and Country on the Middle Danube, Leiden-Boston: Brill, 2006, 264 pp.

5. Hrvatsko-slavonska Vojna Krajina i Hrvati pod vlašcu Osmanskoga Carstva u Ranome Novom vijeku, Zagreb: Leikam, 2007, pp. 108-176; 180-186 (together with Željko Holjevac).

\section{ARTICLES IN BOOKS}

6. "Die Türkenkriege des 16. bis 18. Jahrhunderts in der jugoslawischen Literatur nach 1945," in: Die Türkenkriege in der historischen Forschung, Wien: Deuticke, 1983, 143-164.

7. "Vlasi u Požeškom sandžaku 1545.-81.," in: Dragutin Pavličević, ed Vojna Krajina: povijesni pregled, historiografija, rasprave, Zagreb: Liber, 1984, 193-198.

8. "Besonderheiten der osmanischen Ordnung in Slavonien im 16. und 17. Jahrhundert," Internationales Symposium für osmanische Wirtschafts- $u$. Sozialgeschichte, München 1984, Wiesbaden 1985, 120-127.

9. "Ratovanje i osnivanje upravnih jedinica u srednjoj Slavoniji 1536-1541," in: Vojne krajine u jugoslavenskim zemljama u novom veku do Karlovačkog mira 1699., Beograd: SANU, 1989, 115-124.

10. "Slavonija pod turskom vlašću," in: Đuro Berber and Dušan Čalić, ed., Peti znanstveni sabor Slavonije i Baranje, Vol. 1, Zbornik radova, Vinkovci, 22. i 23. listopada 1987., Osijek: Jugoslavenska akademija znanosti i umjetnosti, Zavod za znanstveni rad u Osijeku, 1991, 67-76.

11. "Zur Verwaltungsgeschichte Mittelslavoniens als Bestandteils des Eyâlet Kanizsa," in: Nagykanizsa török alóli felszabadulásának 300. évfordulóján tartott nemzetközi tudományos konferencia elöadásai, Különlenyomat, Zalai Múzeum 4. 1992, Nagykanizsa, 1992, 73-75. 
12. "Neki problemi tumačenja turskih izvora u vezi s bitkom kod Siska 1593. godine," in: Ivo Goldstein i Milan Kruhek, ed., Sisačka bitka 1593, Zagreb: Zavod za hrvatsku povijest Filozofskog fakulteta Sveučilišta u Zagrebu and Institut za suvremenu povijest - Sisak: Povijesni arhiv, 1994, 125-130.

13. "Bâc and gümrük on the Middle Danube 1540-1614: Terminological Elucidations," in: Jean-Louis Bacqué-Grammont, Ilber Ortayli, Emeri van Donzel, eds., Comité Internationalpour les études préottomanes et ottomanes, VIIe Symposium, Actes, Ankara: Türk Tarih Kurumu, 1994, 463-466

14. "Myth, Legend and History in the Life of a Provincial Ottoman Town: the Case of Dimitrofçe/Sremska Mitrovica," in: Scripta Hierosolymitana, XXXV, Jerusalem: The Hebrew University of Jerusalem, 1994, 70-74.

15. "Hacı Mehmet ağa of Požega, God’s Special Protégé (ca. 1490 - ca. 1580)," in: Géza Dávid, Pál Fodor, eds., Hungarian-Ottoman Military and Diplomatic Relations in the age of Süleyman the Magnificent, Budapest: Loránd Eötvös University, Dept. of Turkish Studies, 1994, 171-181.

16. "Bihać i osmanski obrambeni sustav na sjeverozapadu Bosanskoga ejaleta 1592. 1711.," in: Ivo Goldstein, Mira Kolar-Dimitrijević, Marijan Maticka, eds., Spomenica Ljube Bobana, Zagreb: Zavod za hrvatsku povijest Filozofskog fakulteta Sveučilišta, 1996, 105-111.

17. "Upravna podjela hrvatskih zemalja u sklopu Osmanskog carstva," in: Hrvatske županije kroz stoljeća, Zagreb: Školska knjiga, 1996, 39-47.

18. “Život Jakub-paše, pobjednika na Krbavi 1493.," in: Dragutin Pavličević, ed., Krbavska bitka i njezine posljedice, Znanstveni skup Novi Vinodolski, 22.24. listopada 1993., Zagreb: Hrvatska matica iseljenika, 1997, 175-177.

19. "Introductory Essay on an Understanding of the Triple-frontier Area: Preliminary Turkologic Research," in: Drago Roksandić, ed., Microhistory on the Triplex Confinium, Budimpešta: Institute on Southeastern Europe, CEU, 1998, 125-136.

20. "The Question of Vlach Autonomy Reconsidered," in: Essays on Ottoman Civilization, Proceedings of the XIIth Congress of the CIEPO, Praha 1996, Archiv Orientálni, Supplementa VIII. (1998), Prague 1998, 263-269.

21. "Mass Islamization of Peasants in Bosnia: Demystifications," in: Abdeljelil Temimi, ed., Mélanges prof. Machiel Kiel, Zaghouan: Fondation Temimi pour la recherche scientifique et l'information, 1999, 353-358.

22. "Some Observations on the kapudans in the Ottoman Northwestern frontier Area 16-18 c.," Acta Viennensia Ottomanica, Akten des 13. CIEPOSymposiums, Vienna 1999, 241-246.

23. "Islamizacija seljaštva u Bosni od 15. do 17. stoljeća: demistifikacija," in: Neven Budak et al., Zbornik Mirjane Gross, Zagreb: Zavod za hrvatsku povijest Filozofskog fakulteta Sveučilišta u Zagrebu, 1999, 53-63. 
24. "Migrationen in Slawonien und Syrmien im 16. und 17. Jahrhundert," in: Internationales Kulturhistorisches Symposion Mogersdorf 1997, Zagreb, 2000, 68-74.

25. "Hrvatska i Osmansko Carstvo," in: E. Hercigonja, ed., Hrvatska i Europa. Kultura, znanost i umjetnost. Svezak 2: Srednji vijek i renesansa, Zagreb: HAZU - Školska knjiga, 2000, 63-82.

26. “Osmansko-turska arhivska građa za povijest Slavonskoga Broda i okolice: pregled istraživačkih mogućnosti i nacrt povijesnog razvitka grada i okolice u razdoblju turske vlasti," in: Zlata Živaković-Kerže, ed., Zbornik radova sa znanstvenog skupa u Slavonskom Brodu u povodu 750. obljetnice prvoga pisanog spomena imena Broda, Slavonski Brod: Hrvatski institut za povijest, Podružnica za povijest Slavonije, Srijema i Baranje, 2000, 133-144.

27. "O pogledima akademika Nedima Filipovića na neka pitanja povijesti $\mathrm{BiH}$ XVI. i XVII. stoljeća u svjetlu dostignuća suvremene osmanistike," in: Okrugli sto "Naučno djelo Nedima Filipovića", Sarajevo 23. novembar 1999., Sarajevo: ANUBIH, 2000, 171-176.

28. "Exposing Existing Fallacies Regarding the Captaincies in the Bosnian Frontier Area between the $16^{\text {th }}-18^{\text {th }}$ Centuries," in: Drago Roksandić and Nataša Štefanec, eds., Constructing Border Societies on the Triplex Confinium, Budapest: CEU History Department, 2000, 75-90.

29. “'Autonomija' osmanske Bosne. Nacrt," in: Krešimir Bušić et al., eds, Zbornik uz 70. godišnjicu života Dragutina Pavličevića, Zagreb: Institut društvenih znanosti "Ivo Pilar," 2002, 136-142.

30. "Osmanlı Bosnası"” in: Hasan Celâl Güzel, Kemal Çiçek, Salim Koca, ed., Türkler, vol. 10, Ankara: Yeni Türkiye Yayınları, 2002, 399-405.

31. "Bosanski pašaluk u XVIII. stoljeću," in: I. Golub, ed., Hrvatska i Europa. Kultura, znanost i umjetnost, sv.III: barok i prosvjetiteljstvo (XVII-XVIII. stoljeće), Zagreb: HAZU - Školska knjiga, 2003, 109-113.

32. "Staro i novo u osmanističkim istraživanjima povijesti Bosne i Hercegovine koncem XX stoljeća," in: Enver Redžić, ed., Istorijska nauka o Bosni i Hercegovini u razdoblju 1990-2000., Sarajevo: ANUBIH, 2003, 55-58.

33. “Turska vojna krajina u hrvatskim zemljama: prolegomena za 16. i 17. stoljeće," in: Alexander Buczynski, Stjepan Matković, eds., Hereditas rerum Croaticarum ad honorem Mirko Valentić, Zagreb: Hrvatski institut za povijest, 2003, 85-91.

34. "Croatia and Bosnia: an 'Eternal' Movement from Integration to Dissolution and Back," in: Almut Bues, ed., Zones of Fracture in Modern Europe: the Baltic Countries, the Balkans and Northern Italy, Wiesbaden: Harrassowitz Verlag, 2005, 99-107. 
35. "Bosansko-humski krstjani u turskim vrelima (napomene)," in: Franjo Šanjek, ed., Fenomen "krstjani" u srednjovjekovnoj Bosni i Humu, Sarajevo: Institut za istoriju - Zagreb: Hrvatski institut za povijest, 2005, 407-412.

36. "Rat za oslobođenje 1683.-1699. i njegovi rezultati u istočnoj i središnjoj Hrvatskoj i Slavoniji - Osmanlijska vlast u hrvatskim zemljama - Bosna u 18. stoljeću," in: Mirko Valentić and Lovorka Čoralić, eds., Povijest Hrvata, knj. 2, Od kraja 15. st. do kraja Prvog svjetskog rata, Zagreb: Školska knjiga, 2005, 143-146, 193-207, 311-315.

37. "The Poll-Tax and Population in the Ottoman Balkans," in: Colin Imber and Keiko Kiyotaki, eds., Frontiers of Ottoman Studies: State, Province, and the West, vol. 1, London - New York: I.B. Tauris 2005, 77-89.

38. “Turska Virovitica," in: Julijo Martinčić and Dubravka Hackenberger, eds., 725 godina franjevaca u Virovitici, Zagreb - Osijek: HAZU - Zavod za znanstveni i umjetnički rad u Osijeku, 2006, 17-22.

39. "O izvorima za demografsku povijest Osmanskoga carstva," in: Sašo Jerše, ed., Med Srednjo Evropo in Sredozemljem. Vojetov zbornik, Ljubljana: Založba ZRC, 2006, 247-258.

40. "Demographical Trends in the Ottoman Empire and their impact on Economy: neither the West, nor the East," in: Simonetta Cavaciocchi, ed., Relazioni economiche tra Europa e mondo islamico secc. XIII-XVIII, Grassina: La Monnier, 2007, 55-73.

41. "La conversione di massa di contadini bosniaci all'Islam," in: Luciano Vaccaro, ed., Storia religiosa dell'Islam nei Balcani, Gazzada (VA): Centro Ambrosiano, 2008, 169-188.

42. "Tri slavonska sandžaka - jedno kratko i jedno dugo 'tursko stoljeće”, in: Božo Biškupić, Vesna Kusin, Branka Šulc, eds., Slavonija, Baranja i Srijem vrela europske civilizacije, vol. 1, Zagreb: Printera, 2009, 268-277.

43. "Sitne daće, krupne implikacije," in: Drago Roksandić and Damir Agičić, Spomenica Josipa Adamčeka, Zagreb: FF Press, 2009, 145-165.

44. "The complex origin of the Bosnian ocaklık timar," in: Halil İnalcık Armağanı - I, Ankara: Doğu Batı Yayılnarı, 2009, 142-167.

45. "Remek-djelo habsburške (mletačke?) obavještajne službe: anonimni "geografsko-statistički” opis Bosanskog pašaluka (oko 1625.)," in: Iskra Iveljić, ed., Zbornik Nikše Stančića, Zagreb: FF Press, 2011,77-88.

46. "Whether in comparison with the earlier inventories the cizye registers in XVIII century are doing the research of the demographic tendencies on the Balkans easier," in: Rumen Kovachev, ed., Iz praktikata na osmanskata kancelarija, Sofia: Nacionalna biblioteka "Sv.sv. Kiril i Metodij, 2011, 165-170. 
47. "O pouzdanosti osmanskih katastarskih popisa," in: Nimetullah Hafiz, ed., Proceedings of the IVth International South-East Europe Turkology Symposium, Prizren: Balkan Türkoloji Merkezi 2011, 223-228.

48. "Militärgrenze und »Nationalcharakter « der Kroaten im 17. und 18. Jahrhundert," in: Eckhard Leuschner and Thomas Wünsch, eds., Das Bild des Feindes: Konstruktion von Antagonismen und Kulturtransfer im Zeitalter der Türkenkriege. Ostmitteleuropa, Italien und Osmanisches Reich, Berlin: Gebr Mann Verlag, 2013, 51-54.

49. "The Die-Hardism of the Pre-Reform Ottoman World in Bosnia: Matija Mažuranićs 'Tourist' Visit (1839/40)," in: Norbert Spannenberger an Szabolcs Varga, eds., Ein Raum im Wandel: Die osmanisch-habsburgische Grenzregion vom 16. bis zum 18. Jahrbundert, Stuttgart: Franz Steiner Verlag 2014, 265-274.

50. "Cisr-i kebir-i Ösek," in: Veliki osječki most, Zagreb - Osijek: HAZU, 2014, 91-111.

51. “'Arz-1 haraciyyedir ki ... hasıllarından öşür veyahud sümün veyahud subu veyahud nısfa değin arzin tahammülüne göre harac-1 mukaseme vaz olunur'. The discriminatory vs. uniform rates: less distortionary effects than expected (if any)," in: Vita Litterarum Studiis Sacra, Zbornik u čast Radoslavu Katicicicu, Zagreb: FF Press, 2014, 433-445.

52. "Zagora u razdoblju osmansko-turske vlasti: prema novim spoznajama iz povijesti Sinja i Cetinske krajine," in: Stipe Botica, ed., Leksikon Sinjske alke, Zagreb: Matica hrvatska, Viteško alkarsko društvo Sinj, 2015, 263-274.

53. "Hrvatsko-turski odnosi - pregled povijesne interakcije," in: Katica Jurčević, Ozana Ramljak, Zlatko Hasanbegović, eds., Hrvatska i Turska (povijesnokulturni pregled), Zagreb: Srednja Europa - Institut društvenih znanosti "Ivo Pilar", 2016, 1-20.

54. "The Population of The Ottoman Bosnia in The Eighteenth Century According to the Poll-Tax Records: Methodological Issues," in: Abidin Temizer, ed., Balkan Taribi Araştırmalarına Metodolojik Yaklaşımlar, Istanbul: Libra, 2016, 217-227.

55. "Cisr-i kebir-i Ösek," in: Muhammet Savaş Kafkasyalı (ed.), Balkanlarda İslam, Vol. 3, Ankara: Türk İşbirliği ve Koordinasyon Ajansı (TİKA), 2016, 466-479.

56. "Reading between the lines, interpreting Ottoman cadasdtral surveys anew (some remarks on the discriminatory rates and the so-called "fines")," in: Johannes Zimmermann, Christoph Herzog, Raoul Motika, eds., Osmanische Welten: Quellen und Fallstudien, Festschrift für Michael Ursinus, Bamberg: University of Bamberg Press, 2016, 447-475. 
57. "Le "mystère" quasi insoluble du succès massif de l'islam en Bosnie," in: Philippe Gelez and Gilles Grivaud, eds., Les conversions à l'islam en Asie Mineure, dans les Balkans et dans le monde musulman: comparaisons et perspectives, Atena: École française d'Athènes, 2016, 119-216.

58. "Division of cizye-payers into three classes as foreshadowed in the pre-reform 17 th century 'pseudo-mufassals," in: Srđan Rudić and Selim Aslantaş, eds., State and society in the Balkans before and after establishment of Ottoman rule, Beograd: Istorijski institut - Yunus Emre Enstitüsü, 2017, 319-328.

59. "New Chance for Cliometrics: Examining the Inequalities of Wealth and Income in Ottoman Rural Economy," in: Aşkın Koyuncu, ed., Uluslar arası Balkan Tarihi ve Kültürü Sempozyumu, Vol. 1, Ankara: Çanakkale Onsekiz Mart Üniversitesi, 2017, 246-255.

60. "Zagora u razdoblju osmansko-turske vlasti: prema novim spoznajama iz povijesti Sinja i Cetinske krajine," in: Josip Dukić and Josip Grbavac, eds., 300. obljetnica slavne obrane Sinja 1715. godine (1715. - 2015.), Sinj: Franjevački samostan Gospe Sinjske, Viteško alkarsko društvo Sinj, Grad Sinj i gradovi i općine Cetinske krajine, 2018, 23-34.

61. "Population of the Ottoman Empire in the $16^{\text {th }}$ Century: Challenging the

Braudelian Enthusiasm," in: Ahmet Nuri Yurdusev, ed., Exploring the Commonalities of the Mediterranean Region: Proceedings of the TUBAEMAN Symposium (6-7th November 2017) (Ankara: The Turkish Academy of Sciences, TÜBA, 2019), 51-62.

62. “'Putopis' Evlije Čelebija kao historia phantastica," Damir Agičić, Hrvoje Petrić, Filip Šimetin Šegvić, eds., Zbornik Drage Roksandića (Zagreb: FF Press, 2019), 379-383.

63. "The Ottoman Conquest and Establishment in Croatia and Slavonia," Pal Fodor, ed., The Battle for Central Europe (Leiden: Brill, 2019), 277-286.

64. “Ottoman Osijek as Seen by Evliya Çelebi," Vjeran Kursar, Nenad Moačanin, Kornelija Jurin Starčević, eds., Evliya Çelebi in the Borderlands: New Insights and Novel Approaches to the Seyahatname (Western Balkans and Iran Sections) (Zagreb: Srednja Europa, 2021), 27-38.

\section{ARTICLES IN JOURNALS}

65. “Osječki ili Požeški sandžak," Zbornik Zavoda za povijesne znanosti JAZU 12 (1982), 35-40.

66. "Granice i upravna podjela Požeškog sandžaka," Zbornik Zavoda za povijesne znanosti JAZU 13 (1983), 107-118.

67. "Some Remarks on the Supposed Muslim Tolerance Towards dhimmis," SüdostForschungen 48 (1989), 209-215. 
68. "Ime Gospić u svjetlu turskih izvora," Croatica Christiana periodica 26, 14 (1991), 52-54.

69. "Islam između Save, Drave i Dunava," Prilozi za orijentalnu flologiju 41 (1991), 187-194.

70. "The Croatian Rural Households and Ottoman Fiscal Units," Prilozi za orijentalnu filologiju 42-43 (1992-93), 211-216.

71. "Les Croates et l'Empire Ottoman: quelques réflexions sur leurs rapports," Revue du Monde Musulman et de la Méditerranée 66 (1993), 135-138.

72. "Naseljenost Like i izvori feudalne rente pod turskom vlašću početkom 17. stoljeća," Historijski zbornik 46, 1 (1993), 61-65.

73. "The Historical Fate of Croatia and Turco-Croatian Relations in the Past," Tarih Araşttrmaları Dergisi 16, 27 (1994), 243-255.

74. "Zur Lage des kroatischen Bauerntums während der Osmanenherrschaft," Prilozi za orijentalnu filologiju 44-45 (1994-95), 133-147.

75. “Srijemska Mitrovica 1566: Mit, legenda i povijest," Otium 4/1-2 (1996), 114 117.

76. “Osijek u turskim izvorima," Povijesni prilozi 16 (1997), 33-56.

77. "Osmansko-turski porezni popisi i historijska geografija," Radovi Instituta za brvatsku povijest 30 (1998), 294-299.

78. “Kapudánságok a bosnyák határvidéken a 16-18. században," Aetas 4, (1999), 51-58.

79. "O problemima kartografske identifikacije obavijesti iz osmanskih popisa bosanskih krajišta," Radovi - Zavod za hrvatsku povijest 32-33 (2000), 345-347.

80. "Novije spoznaje o povijesti Kliškog sandžaka prema osmanskim izvorima," Moguínosti 4, 6 (2000), 74-82.

81. "Publishing Ottoman Registers: Some Neglected Points," Archivum Ottomanicum 19 (2001), 103-106.

82. "Pristup ekohistoriji Podravine prema osmanskim izvorima," Ekonomska $i$ ekohistorija 1 (2005), 139-146.

83. "Stanovništvo Bosanskog ejaleta u 18. stoljeću prema popisima glavarine," Rad HAZU 516, Zagreb 2013, 95-120.

84. “Novi’ Evlija Čelebi: autograf'Putopisa'” Književna smotra 46, 173 (3) (2014), 77-90. (with Kornelija Jurin Starčević)

85. “Osmanski Osijek: novi pristup," Rad HAZU 525, Zagreb 2016, 83-106.

86. "Nastanak muslimanskog plemstva u Bosni i Hercegovini: zanemareni aspekti," Rad HAZU, 529, Zagreb 2017, 73-94.

87. “O brojnom stanju osmanske vojske u pohodu na Sinj i Zagoru," Rad HAZU 535, Zagreb 2018, 97 - 105. 
88. "Livno i livanjski kraj u Putopisu Evlije Čelebija i u turskim arhivskim izvorima 17. stoljeća," CLEUNA 3 (2019), 199-207.

\section{POPULAR ARTICLES, REPORTS, CRITICS}

89. "Izvještaj o istraživanju u Arhivu predsjedništva vlade u Istanbulu - travanj 1988.," Zbornik Zavoda za povijesne znanosti JAZU 15 (1989), 115-118.

90. "Hrvatska i Bosna: jedinstvo, dvojstvo ili..?," in: Safvet-beg Bašagić, Znameniti Hrvati Bošnjaci i Hercegovci u turskoj carevini, pretisak, Zagreb: Birotisak, 1994, IX-XXXVIII.

91. "Umjesto pogovora," in: Radoslav Lopašić, Bihać i Bihaćka Krajina: mjestopisne i poviestne crtice, pretisak, Zagreb: Offset Markulin, 1995, 1-7.

92. "Hrvatski sabori u ranom novom vijeku," in: Slava saboru, katalog/mapa, Zagreb: Hrvatski povijesni muzej, 1997, 19-25.

93. "Požega u razdoblju turske vlasti," Encyclopaedia Moderna, XVII/47, Zagreb 1997, 9-12.

94. “À propos d'une publication sur la Bosnie Ottomane," Turcica 33 (2001), 379 84.

95. "Osmanisches Reich," in: Enzyklopädie des Europäischen Ostens, http://www2. uni-klu.ac.at/eeo/ (Klagenfurt 2004)

96. “Croato-Turcica: pregled povijesne interakcije," Hrvatska revija, 15, 2 (2015), 4-13.

97. "O obavijesnom potencijalu osmansko-turske arhivske građe za povijest Srba u Hrvatskoj: uvodne napomene," Tragovi 1 (2018), 191-202.

98. "Hrvatska osmanistika 2001.-2017.: Studije iz prošlosti Bosanskog ejaleta u ranom modernom dobu," in: Dževad Juzbašić, Zijad Šehić, eds., Prilozi o historiografiji Bosne i Hercegovine (2001-2017), Sarajevo: Akademija nauka i umjetnosti Bosne i Hercegovine, 2020, 69-78.

\section{EDITORSHIPS}

99. Ekrem Čaušević, Nenad Moačanin, Vjeran Kursar, eds., Perspectives on Ottoman Studies (Papers from the 18th CIEPO), Berlin: LIT Verlag 2010, 1033 pp. 100. Ekrem Čaušević, Nenad Moačanin, Vjeran Kursar, eds., Osmanlı Sanatı, Mimarisi ve Edebiyatına Bakıs, 18. CIEPO Sempozyumu, Edirne: Trakya Üniversitesi, 2011, 216 pp.

101. Vjeran Kursar, Nenad Moačanin, Kornelija Jurin Starčević, eds., Evliya Çelebi in the Borderlands: New Insights and Novel Approaches to the Seyahatname (Western Balkans and Iran Sections), Zagreb: Srednja Europa, 2021, 230 pp. 


\section{SOURCES}

102. Arhiv Franjevackkog samostana sv. Petra i Pavla na Gorici, Livno: Turske isprave. Priručni katalog (bez TI 39-54, 55-56), Vol. 1, Livno: Franjevački muzej i galerija Gorica - Livno, 2019, 112 pp. (with Michael Ursinus).

\section{REVIEWS}

103. "Igor Karaman, Privreda i društvo Hrvatske u 19. stoljeću, Sveučilište u Zagrebu - Institut za hrvatsku povijest, Zagreb 1972," Godišnjak društva istoričara Bosne i Hercegovine, 20 (1972-1973), 268-271.

104. "Prilozi za orijentalnu filologiju, XVIII-XIX, XX-XXI," Historijski zbornik 27 28 (1974-75), 515-516.

105. "Problemi sinteze povijesti islama - geografska dimenzija u djelu Xaviera de Planhola," Casopis za suvremenu povijest 1 (1979), 142-155.

106. "Prilog Mauricea Lombarda ekonomskoj povijesti islama u ranom srednjem vijeku," Acta historico-oeconomica Iugoslaviae 6 (1979), 137-151.

107. "Vojna Krajina u austrijskoj historiografiji poslije 1945," Radovi Instituta za hrvatsku povijest 14 (1) (1982), 389-395.

108. "Karl Binswanger: Untersuchungen zum Status der Nichtmuslime im Osmanischen Reich des 16. Jahrhunderts, München 1977.," Zbornik Zavoda za povijesne znanosti JAZU 13 (1983), 255-266.

109. "Problemi gospodarske povijesti jugoslavenskih zemalja pod osmanskom vlašću u djelima Bruce McGowana," Acta historico-oeconomica Iugoslaviae 11 (1984), 243-248.

110. "Ludwig Steindorff, Die dalmatinischen Städte im 12. Jahrhundert, KölnWien 1984," Zbornik Zavoda za povijesne znanosti JAZU 15 (1989), 123-133.

111. "Caroline Finkel, The Administration of Warfare: the Ottoman Military Campaigns in Hungary 1593-1606, Beihefte zu Wiener Zeitschrift für die Kunde des Morgenlandes," Arhivski vjesnik, 35-36 (1992), 264-265.

112. "An economic and social history of the Ottoman Empire, ur. Halil Inalcik i Donald Quataert," Prilozi za orijentalnu filologiju, 46 (1996), 240-242.

113. "Ottomans, Hungarians, and Habsburgs in Central Europe (The Military Confines in the Era of Ottoman Conquest, ed. Géza Dávid and Pál Fodor, Brill, 2000)," Wiener Zeitschrift für die Kunde des Morgenlandes 92 (2002), 310-318.

114. "Markus Koller, Bosnien an der Schwelle zur Neuzeit. Eine Kulturgeschichte der Gewalt (1747-1798), Südosteuropäische Arbeiten, 121, R. Oldenbourg Verlag, München 2004," Wiener Zeitschrift für die Kunde des Morgenlandes 98 (2008), 515-516. 
115. “Olga Zirojević, Turci u Podunavlju. Drugi deo. Pančevo, 2010.” SüdostForschungen 72 (2013), 433.

116. "Fazileta Hafizović: Popis sela sandžaka Krka, Klis i Hercegovina, oslobođenih od Mletačke Republike 1701. Zagreb i Sarajevo: Prosvjeta, Filozofski fakultet i Orijentalni institut, 2016.," Tragovi 1 (2018), 243-245.

\section{OTHER CONTRIBUTIONS}

117. Walter Beltz, Mitologija Kur'ana: čežnja za rajem, Zagreb: GZH, 1982. (translation from German, $226 \mathrm{pp}$.)

118. Maxime Rodinson, Marksizam i islamski svijet, Zagreb: Globus 1988 (translation from French, 314 pp.)

119. Josef Matuz, Osmansko Carstvo, Zagreb: Školska knjiga, 1992 (translation from German, 223 pp. + translator's note)

121. Omar Hajjam, 100 pjesnika svijeta, Zagreb: Mladost, 1984, 120-122 (essay)

122. Hafiz, 100 pjesnika svijeta, Zagreb: Mladost 1984, 171-177 (essay+translation)

123. Ivan Erceg, "Turska osvajanja i organizacija proizvodnje u Dalmaciji i njihov odraz na privredni život Hrvatske," Zbornik Cetinske krajine 4, Sinj 1989, 9-54 (transcription and translation of Ottoman documents, pp. 34-35)

124. "Poetski svijet Yunusa Emrea," Hrvatski radio, Zagreb 1991, III program (60 minutes radio show)

125. "Vukovar i Ilok u turskom razdoblju," Hrvatski radio, Zagreb, June 1991, II program (radio)

126. "Požega u razdoblju turske vlasti," Hrvatski radio, Zagreb 1995, III program (radio)

127. "Marginalije uz temu 'Croato-Turcica', Thesaurus Archigymnasii," Zagreb, 2007, 509-515.

128. Aralica, Tomislav: Hladno oružje - jatagani u Hrvatskoj, Muzej seljačkih buna, Gornja Stubica 1997 (translation of Arabic inscriptions in the catalogue of the exhibition, pp. 18-23).

129. Turkologischer Anzeiger/Turkology Annual 21/1995, Wien 1997. cited under no. 615,938,939,941,942,1252. TA 22-23 Wien 1998. cited under no. 2699. TA 22-23 Wien 1998. cited under no. 1406, 1407, 1464, 1466, 1467, b. 1465, Rez. 168. ISSN 0084-0076.

130. “Ive Mažuran, Hrvati i Osmansko carstvo, Zagreb 1998," Vijenac, April 23,1998.

131. Balkanske i orijentalne puske, Zagreb: Hrvatski povijesni muzej, 2001 (transcription of Arabic inscriptions). 


\section{ENTRIES (ENCYCLOPAEDIAS, LEXICONS)}

132. Enciklopediju hrvatske povijesti i kulture, Igor Karaman, ed., Zagreb 1980: Požeški i Pakrački sandžak, 485-487; Tursko (Osmansko) carstvo, 700701.

133. İslam Ansiklopedisi, Türkiye Diyanet Vakf1, Istanbul: (1) Diyakova, (2) Foça, (3) Hırvatistan, (4) İzvornik, (5) Karadağ, (6) Kırka, (7) Klis, (8) Pojega, (9) Siska, (10) Slavonya, (11) Srem, (12) Zaçasna, (12) Zagreb.

134. Hrvatski leksikon, vol. II, Zagreb, 1997: 54 entries concerning Ottoman rule in Croatian lands ( 40 pp.).

135. Hrvatska Enciklopedija: entry "Hrvati” (Early Modern Era) (10 pp.).

136. Encyclopedia of the Ottoman Empire, Gábor Ágoston - Bruce Masters, eds., New York, 2009: Croatia, 163-164; Ragusa, 477-478; Dalmatia, 168; Uskoks, 579-580; Drava, 188-189; Vlachs, 585-586. 